Dr OLEG JEKNIĆ, docent

Fakultet za medije i komunikacije, Univerzitet Singidunum

Beograd, Republika Srbija

oleg.jeknic@fmk.edu.rs

originalan naučni rad

UDK: 791.622(497.11)"1897/1947"

primljeno: 26. februar 2019.

791.1(497.11)

prihvaćeno: 22. maj 2019.

https://doi.org/10.29362/ist20veka.2019.2.jek.65-84

\title{
TRI POČETKA SRPSKOG IGRANOG FILMA: NAČINI NARACIJE I DRUŠTVENI KONTEKST
}

APSTRAKT: Autor zastupa tezu da srpsku kinematografiju karakteri$\check{s}$ e diskontinuitet, te da svaki njen novi početak, u oblasti igranog filma, ima osoben način naracije. Mogu se izdvojiti tri početka: 1911. godine kada je snimljen prvi igrani film u Kraljevini Srbiji, 1922. kada je obnovljena proizvodnja na teritoriji Srbije u okviru Kraljevine SHS, i 1947. kada je snimljen prvi igrani film u socijalističkoj Srbiji. Diskontinuitet je nastao primarno kao posledica prekida proizvodnje koje su uslovila dva svetska rata, ali su uticaj imale $i$ druge društvene okolnosti. Analizom izabranih primera, tipskih za posmatrani period, autor pokazuje da su kulturni i profesionalni uticaji, koji su oblikovali naraciju tih filmova, sukcesivno dolazili iz Francuske, SAD i SSSR-a. I pored diskontinuiteta, neke narativne karakteristike povezuju većinu filmova posmatranog perioda, a to su: melodramska struktura zapleta, ženski likovi kao nosioci značenja, atmosfera ugroženosti i neophodnost da se glavni junak žrtvuje za opšte dobro.

KLJUČNE REČI: kinematografija, naracija, narativni modusi, istorija filma, dramaturgija, Srbija, Jugoslavija

\section{Uvod}

Od kada su snimljeni prvi filmski kadrovi na teritoriji Srbije 1897. godine $^{1}$ pa do 1947, kada je proizveden zvanično prvi igrani film nove Jugoslavije u okviru jednog beogradskog studija (Slavica, reditelj Vjekoslav Afrić, Avala film, Beograd), filmska proizvodnja u Srbiji je bila u svakom pogledu nerazvijena. Prema onome što nam je danas poznato, od 1897. godine pa do prvog zvučnog igranog filma proizvedenog na prostoru bivše Jugoslavije (Nevinost

\footnotetext{
${ }^{1}$ U februaru i martu 1897. Francuz Andre Kare (André Carré) u Beogradu je snimio pet jednominutnih dokumentarnih ,storija“, od kojih su dve prikazane publici (Tramvajska stanica i Izlazak radnika), ali nijedna nije sačuvana do danas. Dejan Kosanović, Počeci kinematografije na tlu Jugoslavije 1896-1918 (Beograd: Institut za film i Univerzitet umetnosti, Beograd, 1985), 63-64.
} 
bez zaštite, r. Dragoljub Aleksić, 1943), ukupno su snimljena svega 22 igrana filma različitih dužina. ${ }^{2}$ Do danas ih je sačuvano samo sedam.

Do kraja Drugog svetskog rata na teritoriji današnje Srbije nije postojala nijedna producentska kuća koja je proizvodila igrane filmove u kontinuiranom periodu dužem od tri godine. Jedna od najaktivnijih je bila Državna radionica filmova pri Ministarstvu narodnog zdravlja, koja je u toku 1922. i 1923. godine proizvela četiri namenska igrana filma srednje dužine. To su bili prvi srpski igrani filmovi snimljeni posle 1912. godine. ${ }^{3}$ Ostale producentske kuće su proizvele najviše po dva srednja ili duža igrana filma nakon čega su prestajale sa radom ili bi nastavile sporadičnu proizvodnju žurnala, dokumentarnih ili kratkih reklamnih filmova čime su održavale kakav-takav produkcioni kontinuitet. U najvećem delu posmatranog perioda teško da se izraz kinematografija uopšte i može upotrebiti za tadašnju filmsku delatnost na teritoriji Srbije. ${ }^{4}$

Razlozi za takvo stanje su višestruki. U Kraljevini Srbiji a, u prvom periodu, i u Kraljevini SHS/Jugoslaviji nisu ulagana državna sredstva u civilnu proizvodnju filmova. Država je igrani film sve do 1931. godine i donošenja Zakona o uređenju i prometu filmova tretirala kao nepriznatu kulturnu delatnost pa je, čak, deo prihoda od prodatih filmskih ulaznica bio namenjen za razvoj pozorišta (tzv. pozorišni dinar). Novac koji su pojedinci kao producenti mogli prikupiti i uložiti u snimanje filma bio je vrlo ograničen, a ni taj mali ulog se nije mogao vratiti iz domaće distribucije. Inostrano tržište nije bilo zainteresovano za srpske igrane filmove jer ih nije krasila nikakva specifičnost, ni u sadržaju ni u formi. Zvuči paradoksalno, ali zapravo je tek u ratu (Prvom svetskom) država Srbija prvi put učinila nešto konkretno u cilju formiranja neke vrste organizovane kinematografske aktivnosti. Po uzoru na Francusku vojsku, 1916. godine na Krfu je formirana Filmska sekcija pri komandi Srpske vojske. ${ }^{5}$ Tada je i kupljena prva filmska tehnika - dve kamere i tri kinoprojektora. Tu su se, u Kinematografskom odeljenju, obučavali rukovaoci filmskom opremom, od kojih će neki kasnije ostaviti značajnog traga u srpskom igranom filmu (pre svega Mihailo Mihailović - Mika Afrika). ${ }^{6}$ Ratovi su ipak bili ključni uzrok nerazvijenosti srpske kinematografije. Od 1912. do 1918. jedina konstanta u životu u Srbiji su bile vanredne, ratne okolnosti, a razaranja su teško osiromašila državu u svakom pogledu a pre svega ljud-

\footnotetext{
2 Taj broj podrazumeva i srednjemetražne i kratkometražne filmove. Videti: Дејан Косановић, „Грешница без греха greha“, Нови Филмограф, година 1, бр. 1, (јесен 2005/зима 2006), 104.

${ }^{3} \mathrm{U}$ najvećem delu perioda kojim se bavimo Srbija nije postojala kao samostalna država, te će se u ovom radu pod izrazom srpski film podrazumevati filmovi koji su proizvedeni od strane pojedinaca ili produkcionih kuća sa teritorije koju obuhvata današnja Srbija.

${ }^{4} \mathrm{U}$ stručnoj literaturi pod pojmom kinematografija podrazumevaju se najmanje tri delatnosti koje moraju funkcionisati istovremeno: organizovana proizvodnja, distribucija i prikazivanje filmova. Neki autori, na primer Kosanović, tu uključuje i filmsku kritiku, filmsku štampu, izdavačku delatnost i školovanje za film. Dejan Kosanović, Kinematografija i film u Kraljevini SHS/Kraljevini Jugoslaviji 1918-1941 (Beograd: Filmski centar Srbije, 2011), 5. Ako se uzme u obzir ovaj stroži kriterijum, do 1945. godine kinematografija je postojala samo u periodu od 1931. do 1941.

${ }^{5}$ D. Kosanović, Počeci kinematografije..., 113.

${ }^{6}$ Mihailo Mihailović je nakon Prvog svetskog rata pored ostalog bio i šef pomenute Državne filmske radionice, gde je radio i kao snimatelj igranih filmova koje je proizvela ta institucija.
} 
skom. ${ }^{7}$ Među stradalima u Prvom svetskom ratu brojne su filmadžije, i to one najznačajnije - prvi filmski producenti Svetozar Botorić, Đorđe Đoka Bogdanović i Krsta Cvetković. ${ }^{8}$ Zbog toga, posle Prvog svetskog rata srpska kinematografija počinje doslovno od nule, i u materijalnom i u stvaralačkom pogledu.

Ista situacija se ponavlja tridesetak godina kasnije, nakon Drugog svetskog rata. Proizvodnja je prekinuta, mnogi su poginuli, a od onih koji su preživeli rat mnogi nisu preživeli ideološki sud nove vlasti. Uz mnoge teškoće, samo su Mihailo Al. Popović, Josip Novak i Stevan Mišković, srpski autori iz „stare Jugoslavije“, nastavili da se bave poslom snimatelja igranih filmova, i to tek u drugoj polovini 1950-ih. Ostali predratni stvaraoci su se u novoj državi bavili drugim poslovima ili su ostali u struci ali su bili marginalizovani. ${ }^{9}$ Tako je srpska kinematografija, nakon prekida uslovljenog Drugim svetskim ratom, ponovo počela gotovo od nule.

Proizvodnja srpskih igranih filmova, dakle, imala je tri početka: prvi, formalno 1897. kada su snimljeni prvi filmski kadrovi u Beogradu a suštinski 1911. kada je snimljen i prikazan prvi dugometražni igrani film Karađorđe (koji je do kraja 1920-ih izgubljen a onda pronađen 2003, baš na vreme za proslavu 200-godišnjice Prvog srpskog ustanka); drugi, krajem 1920-ih, kada nastaju prvi ozbiljniji dugometražni filmovi, neposredno pre kao i nakon donošenja prvog Zakona o uređenju prometa filmova, kojim se pokušalo sistematski rešiti pitanje finansiranja filmske proizvodnje čime bi se ona podigla iz pepela; i treći, 1945. godine, kada formalno nastaje kinematografija „nove Jugoslavije“ po sovjetskom modelu, a suštinski 1947. kada nastaje prvi igrani film Slavica, hrvatskog reditelja Vjekoslava Afrića. ${ }^{10}$

U pogledu pripadnosti nekom širem kulturnom modelu, koji se indirektno ogledao i u narativnoj strukturi tih filmova, kako ćemo u nastavku pokazati, prvi početak srpskog filma bio je u znaku francuskog uticaja, drugi u znaku holivudskog filma a treći je bio pod nedvosmislenim uticajem SSSR-a (koji će već nakon 1948. biti doveden u pitanje).

\section{Istorijski modusi filmske naracije}

Narativ je pojam koji je u savremeno doba postao nerazdvojiv deo vokabulara svih teorija koje pokušavaju da objasne najrazličitije aspekte ljudskog dela-

\footnotetext{
7 Prema istraživanjima Miloša Jagodića, demografski gubici Kraljevine Srbije između 1910. i 1921. godine iznosili su 1.253.811 ljudi. Милош Јагодић, „Процена демографских губитака Срба у периоду 1910-1921”, Српске студије, бр. 6, (2015), 19-21.

${ }^{8}$ Dejan Kosanović identifikuje ukupno četiri filmska proizvođača u Srbiji do 1915. godine: Svetozara Botorića, vlasnika bioskopa „Pariz“; braću Savić, vlasnike „Modernog bioskopa“; braću Cvetković, vlasnike bioskopa „Kolarac“; i Đoku Bogdanovića, vlasnika bioskopa „Kazina“. D. Kosanović, Počeci kinematografije..., 75.

${ }^{9}$ Kosta Novaković, najznačajniji srpski producent, reditelj i snimatelj između dva svetska rata, nakon oslobođenja radio je na Medicinskom fakultetu u Foto-filmskom zavodu.

${ }^{10} \mathrm{U}$ savremenoj filmskoj istoriografiji Slavica se smatra srpskim filmom jer je producent tog filma bila Avala film, preduzeće republike Srbije sa sedištem u Beogradu, iako je priča filma vezana za Hrvatsku, gde je i sniman sa gotovo celokupnom ekipom iz Hrvatske.
} 
nja. Široko je prihvaćeno uverenje da čovek zapravo i ne može formulisati iskustvo sopstvenog postojanja osim u formi narativa tj. priče. Žan Fransoa Liotar (Jean-François Lyotard) naraciju (pripovedanje) naziva ,suštinskom formom svakodnevnog ljudskog saznanja“. ${ }^{11}$ Poter Abot narativ definiše kao „osnovni način na koji ljudska vrsta organizuje svoje shvatanje vremena“ ${ }^{12}$ Dugim rečima, za većinu onih koji promišljaju narativ, to je forma u kojoj se izražava sama ljudska svest.

U oblasti filma takođe postoje brojne teorije filmske naracije. ${ }^{13}$ Dejvid Bordvel (David Bordwell), teoretičar filma kognitivističkog usmerenja, autor je teorije filmske naracije koja je posebno zanimljiva za temu ovog rada, i to iz dva razloga. Prvo, zato što je na osnovu svoje teorije napravio jasnu i sveobuhvatnu sistematizaciju istorijskih modusa ${ }^{14}$ filmske naracije, koja gotovo u potpunosti pokriva razdoblje kojim se ovde bavimo. Drugo, zato što njegova teorija primarni značaj daje gledaocu i njegovim misaonim procesima koji su, kao šablonske forme, jednim delom rezultat evolutivnog procesa ali su oblikovane i kulturnim i opštim društvenim okolnostima. ${ }^{15}$ Ta veza društvenog konteksta i načina konstruisanja naracije nas ovde posebno zanima. Zbog obima ovoga rada nećemo ulaziti u detalje Bordvelove teorije, ali ćemo objasniti osnovne pojmove i teze.

Po Bordvelu, naracija u igranom filmu je ,proces u kom siže i stil filma u sadejstvu daju gledaocu naznake i kanališu njegove aktivnosti vezane za izgradnju fabule“.$^{16}$ Fabula ili priča filma, dakle, nastaje kao rezultat aktivnog procesa koji se odvija u ljudskom umu i koji je baziran na prethodnom životnom i gledalačkom iskustvu kao i na prirođenim, evolutivno razvijenim kognitivnim mehanizmima. Fabulom Bordvel naziva uzročno-posledični, hronološki niz događaja koji čine priču jednog filma (koja po toj teoriji objektivno ne postoji na filmskom platnu), siže je način prezentacije fabule u datom filmu (ono što se obično zove zaplet), a stil je upotreba filmskih sredstava izražavanja u cilju audio-vizuelnog prezentovanja sižea (to je i jedini čulni aspekt filma). ${ }^{17}$

Analizirajući tipove naracije u igranom filmu kroz celu istoriju svetskog filma, Bordvel ih je grupisao u pet istorijskih modusa. To su klasični, umetnički, istorijsko-materijalistički, parametarski i ,godarovski“. Poslednja dva modusa su zapravo podvrste prethodnih (pre svega umetničkog), pa ćemo zato uzeti u

\footnotetext{
11 Jean-François Lyotard, The postmodern condition, Theory and History of Literature, vol. 10 (Minneapolis: University of Minnesota Press, 1984), 19, navedeno prema: H. Poter Abot, Uvod u teoriju proze (Beograd: Službeni glasnik, 2009), 24.

${ }^{12}$ Isto, 27.

${ }^{13}$ To su, na primer, teorije Edvarda Branigana (Edward Branigan), Sejmora Četmena (Seymour Chatman) ili Bila Nikolsa (Bill Nichols).

${ }^{14}$ Izraz modus, umesto način naracije, koristi se u srpskom prevodu knjige Naracija u igranom filmu (prevela Slavica Miletić) kao specifično Bordvelov teorijski pojam, pa se kao takav i ovde upotrebljava. Više o ovom pojmu u: Dejvid Bordvel, Naracija u igranom filmu (Beograd: Filmski centar Srbije, 2013), 174.

15 „Očigledno je, međutim, da koliko god sposobnost formiranja shema počiva na urođenim mentalnim sposobnostima, posmatrači uče određene prototipe, šablone i procedure društvenim putem." Isto, 173, kurziv u originalu.

${ }^{16}$ Isto, 67.

${ }^{17} \mathrm{O}$ ovim važnim pojmovima za teoriju naracije više u: D. Bordvel, $n$. d., 63-68.
} 
obzir samo prva tri glavna modusa koja su i zastupljena u našoj kinematografiji u posmatranom periodu.

Kako Bordvel kaže, svi mi ,intuitivno“ prepoznajemo običan, lako razumljiv film. Filmovi nastali u Holivudu između 1917. i 1960. najbolji su primeri klasične naracije (narativnog modusa klasičnog filma). „Klasičan holivudski film prikazuje psihološki definisane pojedince koji se bore da reše jasno postavljen problem ili da postignu određeni cilj. Tokom borbe dolaze u sukob sa drugima ili sa spoljašnjim okolnostima. Priča se završava pobedom ili porazom, rešenjem problema i nedvosmislenim ostvarenjem ili neostvarenjem cilja."18 Tipični primeri ovakvog modusa naracije su, recimo, svi poznati filmovi Džona Forda ili Alfreda Hičkoka.

Za razliku od naracije klasičnog filma, koja poreklo ima u tradiciji ,dobro skrojenog pozorišnog komada" s kraja 19. veka, naracija umetničkog filma nastaje pod uticajem modernizma u književnosti. Stoga, nasuprot objektivnom realizmu klasičnog filma, u umetničkom imamo „ekspresivni“ ili subjektivni realizam, a namesto jasno određenog glavnog junaka imamo protagonistu nedovoljno jasnih osobina, motiva ili ciljeva, koga muče metafizička pitanja o svrsi i smislu ljudske egzistencije ili problemi poput otuđenja i osećaja životnog nezadovoljstva. Kraj umetničkog filma je obično „otvoren“, ambivalentan, a film često ima epizodičnu strukturu u kojoj scene mogu biti poređane i bez poštovanja hronološkog reda, ili sa velikim elipsama (skokovima $u$ vremenu) i razlabavljenim uzročnoposledičnim vezama. Ako se klasični (,holivudski“") filmovi mogu nazvati „filmovima akcije“, umetnički filmovi bi onda mogli biti nazvani „filmovima stanja“. Tipični filmovi umetničkog modusa nastajali su 1920-ih u Nemačkoj u okviru filmskog ekspresionizma i u Francuskoj u impresionizmu, a kasnije, nakon Drugog svetskog rata, u italijanskom neorealizmu, francuskom novom talasu, kao i u filmovima osobenih autora koji su prevazilazili nacionalne i žanrovske odrednice, kao što su Ingmar Bergman, Alen Rene ili Mikelanđelo Antonioni.

Poseban način naracije karakteriše sovjetske filmove nastale između 1925. i 1933. godine. To je period kada se u Sovjetskom Savezu u raznim umetnostima sprovode eksperimenti u formi, sa ciljem da se na naučnoj osnovi isplanira njihovo propagandno dejstvo. „Naracioni principi na kojima počiva i sredstva koja koristi suprotni su holivudskim normama, a ciljevi su otvoreno didaktički i ubeđivački. (...) Sovjetski film je eksplicitno tendenciozan kao roman s tezom; svet fabule čini niz apstraktnih pretpostavki čiju valjanost film istovremeno pretpostavlja i potvrđuje." ${ }^{\text {19 }}$ Jedna od najočiglednijih karakteristika ovog načina naracije jeste promena u koncepciji glavnog junaka. Glavni junaci u ovim filmovima ne postoje kao individue. Oni su prototipovi cele klase, sredine ili istorijske epohe. „Njihova uzročnost je definisana kao nadindividualna, a njen izvor su društvene snage koje opisuje boljševička doktrina. Likovi su zato uglavnom definisani svojim klasnim položajem, poslom, društvenim aktivnostima i političkim gledištima. ${ }^{620}$ Za filmove ovog tipa karakteristična su dva narativna obrasca - takozva-

\footnotetext{
${ }^{18}$ Isto, 182.

${ }^{19}$ Isto, 266.

${ }^{20}$ Isto.
} 
na „struktura sukobljavanja“, gde psihološki nepromenljiv junak predstavlja neku grupu u svojoj borbi s protivnicima, i ,struktura naukovanja“, gde tipičan pojedinac prelazi put od neznanja do znanja i od pasivnosti do aktivnosti. ${ }^{21}$ Jedna od specifičnih karakteristika ovih filmova jeste i njihova ,samosvest“" (film gledaoca „,podseća“" na činjenicu da gleda film a ne realnost) koja se postiže načinom kadriranja (frontalnost figura i obraćanje junaka direktno u kameru) i montažom (filmski prizor se ne ,prikazuje“ nego ,konstruiše“, što zahteva povećanu aktivnost gledaoca u stvaranju mentalne slike filmskog prostora na osnovu velikog broja kratkih kadrova). Tipični filmovi istorijsko-materijalističkog modusa naracije ujedno su i najpoznatiji sovjetski filmovi tog perioda: Oklopnjača Potemkin (Бронено́сец «Потёмкин», r. S. M. Ejzeštejn, 1925), Mati (Mamb, r. V. Pudovkin, 1926) i Zemlja (Земля, r. A. Dovženko, 1930).

\section{Prvi početak srpskog filma - umetnička naracija}

Bordvelovi istorijski modusi naracije odnose se na filmove nastale nakon 1917. godine, jer je uobičajeno stanovište u filmskoj istoriji i teoriji da su se tek otprilike $\mathrm{u}$ to vreme u SAD i Evropi standardizovali svi bitni oblici filmskog izraza koje koristimo do danas (način kadriranja, glume i montaže, filmska dramaturgija). Pošto je prvi srpski igrani film snimljen pre 1917, kulturni uticaji koji su ga oblikovali postaju uočljiviji kroz prikaz konkretnih istorijskih okolnosti u kojima je nastao nego kroz analizu njegove narativne strukture koja je, kao i u gotovo svim evropskim filmovima tog vremena, bila više proizvod normi direktno preuzetih iz pozorišne tradicije nego razvijene svesti o specifičnim izražajnim mogućnostima novog medija.

Svetozar Botorić, vlasnik hotela Pariz, poslanik Radikalne stranke, predstavnik u to vreme najveće francuske i svetske filmske kuće Braća Pate (Pathé Frères) za Srbiju, producent je prvih srpskih dugometražnih igranih filmova Život $i$ delo Vožda Karađorđa i Ulrih Celjski $i$ Vladislav Hunjadi. ${ }^{22}$ Oba filma režirao je pozorišni glumac i reditelj Ilija Stanojević 1911. godine uz, pretpostavljamo, veliku pomoć čoveka koji je u tom trenutku jedini imao iskustva sa filmom - snimatelja Luja de Berija (Lous de Berry). Karađorđe je nastao kao rezultat delovanja Udruženja za snimanje srpskih filmova - grupe intelektualaca koju su činili pomenuti Botorić, zatim glumac i reditelj Kraljevskog srp-

${ }^{21}$ Susan Rubin Suleiman, Authoritarian Fictions: The Ideological Novel as a Literary Genre (New York: Columbia University Press), 101-109, navedeno prema D. Bordvel, n. d., 267.

${ }^{22}$ Poznati su i neki raniji pokušaji snimanja igranog filma na teritoriji današnje Srbije. Somborac Ernest Bošnjak (Bosnyák Ernő) 1909. godine samostalno je proizveo film U carstvu Terpsihore, koji nije sačuvan. Stevan Jovičić tvrdi da je u knjizi Branislava Nušića Hadži Loja, izdanje iz 1908. godine, našao podatak da je filmskom kamerom te godine snimljena cela istoimena predstava. Stevan Jovičić, „Kinematografija u Srbiji 1896-1941“, Südslavistik online, Nr. 2, (2010), 25. http://www.suedslavistik-online.de/02/jovicic.pdf (pristupljeno 16. 2. 2019). Budući da nema potpunih podataka o sadržaju, formi i, posebno, o prikazivanju ova dva filma, kao početak proizvodnje srpskih igranih filmova ćemo uzeti film Karađorđe iz 1911, što je i uobičajen stav o ovom pitanju u srpskoj filmskoj istoriografiji. 
skog narodnog pozorišta „Čiča“ Ilija Stanojević i beogradski trgovac i zakupac Klasne lutrije Ćira Manok. Ilija Stanojević je svedočio da je upravo Botorić došao na ideju da se napravi jedan veliki, narodni film. ${ }^{23}$

O filmu Ulrih Celjski $i$ Vladislav Hunjadi, koji je prvi snimljeni srpski film ali drugi prikazani, zbog obima ovog rada nećemo ništa više reći, mada su objašnjenja kako je do snimanja tog filma došlo zanimljiva jer ukazuju na simptomatičan splet profesionalnih (filmskih) i političkih uticaja. ${ }^{24}$

Botorić je veoma ambiciozno pristupio Karađorđu pa je taj film prevazišao svoje uzore kao i standarde svog vremena, pre svega po dužini - trajao je u originalnoj verziji preko jednog sata. ${ }^{25}$ Ta dužina je bila neophodna da bi bile prikazane sve bitne epizode iz Karađorđevog života, koje su zamislili Botorić i njegov scenaristički tim koji su činili Čiča Ilija, Ćira Manok i izvesni pop Savković. ${ }^{26}$ Osim trajanja, nestandardna je bila i montaža u Karađorđu. U njemu, naime, postoji scena čija radnja je prikazana u više od jednog kadra. To je scena „Boj na Mišaru“" u kojoj postoji naizmenično smenjivanje kadrova u kojima vidimo ustanike koji nešto gledaju, nakon čega dolazi kadar onoga što gledaju - tursku vojsku koja se u opštem planu kreće ka kameri. To jeste rudimentarni oblik montaže po principu kadar -kontrakadar ali je sasvim neobičan za taj period u evropskom filmu (kada je vladao princip: jedna scena - jedan kadar), a posebno za prvi ili drugi film jednog autora, producentske kuće i gotovo cele ekipe. Pokreti kamere, koji postoje u par kadrova i koji su takođe van standarda za ovaj žanr u ovom periodu, više su posledica pokušaja da se koriguje kompozicija kadra (poremećena, recimo, ulaskom psa u vidno polje kamere) nego kreativne odluke snimatelja ili reditelja. Sve u svemu, iako su generalno ostali u granicama normi svog vremena, Botorić i ekipa su vešto iskoristili nasleđe francuskog Film d' Art $^{27}$ (velika nacionalna tema, izbor poznatih pozorišnih glumaca, postavka scene uz upotrebu dubinskog mizanscena) sa ciljem da proizvedu delo koje će mobilisati gledaoce u pravcu podrške dinastiji koja je bila na vlasti a čiji je osnivač bio i glavni junak ovog filma. Naža-

${ }^{23}$ Videti: D. Kosanović, Počeci kinematografije ..., 78.

${ }^{24}$ Više u: Bosa Slijepčević, Kinematografija u Srbiji, Crnoj Gori, Bosni i Hercegovini 1896-1918 (Beograd: Institut za film Beograd, 1982); Александар Саша Ердељановић, „Продуцент Светозар Боторић и његови филмови (II део)“, Нови Филмограф, година 1, бр. 2, (2006), 104-108.

${ }^{25}$ Verzija koja je pronađena u filmskom arhivu u Beču 2003. godine traje oko 48 minuta, ali joj nedostaju neke scene. Na osnovu zapisa iz štampe tog vremena smatra se da je u originalu film mogao trajati i celih 88 minuta. А. С. Ердељановић, „Продуцент Светозар Боторић и његови филмови (І део)“, Нови Филмограф, година 1, бр. 1, (2005/06), 98.

${ }^{26}$ „Glavni i najveći deo scenarija očigledno je rađen na osnovu drame „Kara-Đorđe“ poznatog pisca, reditelja i glumca Narodnog pozorišta Miloša Cvetića, epizoda sa dahijama preuzeta je iz narodne pesme „Početak bune na dahije“ koju je verovatno spevao slepi guslar Filip Višnjić, a svakako su korišćena i druga, pre svega istorijska i memoarska dela o Karađorđu kao što su prvi deo njegove biografije „Karađorđe“ Milenka M. Vukićevića i zbirka anegdota, priča i crtica „Karađorđe u govoru i u tvoru“ Milana Đ. Milićevića.“ А. С. Ердељановић, „Продуцент Светозар Боторић и његови филмови (I део)“, 97.

${ }^{27}$ Film d'Art je bio svetski poznat žanr filmova iz 1910-ih koji su nastajali po pozorišnim tekstovima i sa pozorišnim glumcima. On je bio namenjen intelektualnijoj publici, dok su ,za narod“ većinski proizvođeni popularni kriminalistički serijali kao što su na primer Fejadovi (Louis Feuillade) Fantômas, Les Vampires and Judex ili komedije Maksa Lindera (Max Linder). 
lost, finansijska podrška dinastije producentima očigledno nije bila odgovarajuća pa je Botorić odmah prestao sa daljom proizvodnjom igranih filmova.

Što se načina naracije tiče, ona je u Karađorđu u najvećem delu klasična. Glavni junak je jasno psihološki određen lik (prek i pravičan, borac za slobodu). Njegov cilj je određen i realističan (osloboditi sebe i narod od turskog jarma). Kraj filma je „zatvoren“ (nema pitanja šta će dalje biti sa junakom, sve linije priče su završene) što je takođe karakteristika klasičnog modusa, ali je i negativan (glavni junak umire), što je donekle u suprotnosti sa tipičnim, holivudskim hepiendom. Uz to, u načinu povezivanja scena primećujemo primat hronologije nad dramaturgijom - sekvence uglavnom nisu objedinjene jedinstvenom dramskom radnjom već istorijskom hronologijom, što je još jedna od karakteristika modusa umetničkog filma.

Značenjska analiza Karađorđa ukazuje da je žrtvovanje implicitna tema filma. Eksplicitni dramski sukob u filmu je vezan za fizički sukob Karađorđa i pobunjenih Srba sa njihovim turskim osvajačima. Taj sukob je često dat $u$ formi akcionog dešavanja, iako se radi, kao što je rečeno, o biografskom delu komponovanom po hronološko-epizodijskom načelu. Unutrašnji dramski sukob glavnog junaka, koji se doduše više naslućuje nego što je pokazan, proizlazi iz sklopa njegovog karaktera, oblikovanog snažnim epskim nacionalnim nasleđem i istorijskim okolnostima. To je drama ličnog žrtvovanja zarad viših, opštih ciljeva, pre svega zarad nacionalnog oslobođenja. Tako su i moralno pravdani neki radikalni postupci glavnog junaka. Ubistvo očuha ${ }^{28}$ pokazano je kao direktno sprovođenje majčine volje a ubistvo „obesnog Turčina“, na početku filma, ili ubistvo brata Marinka, nastaju kao proizvod ne samo njegovog ,prekog“ karaktera nego i potrebe da se ne iznevere očekivanja okoline. Naravno, najveća žrtva koju Karađorđe treba da podnese, doduše ne svojevoljno, jeste da preda svoju glavu na oltar otadžbine. To je i poslednja scena filma koja i danas u gledaocima izaziva osećaj tragike, ne samo zbog sudbine glavnog junaka filma nego i zbog osećaja da se radi o priči koja potvrđuje obrasce nacionalnog mita - neminovno žrtvovanje za državni interes koje dolazi kao posledica unutrašnje nacionalne nesloge.

Tragična je i sudbina producenta Botorića. U vreme austrougarske okupacije Beograda rekviriran mu je bioskop a on odveden u logor Nežider, gde je umro u novembru 1916. Činilo se da ga ni njegovi filmovi neće mnogo nadživeti - Karađorđe je poslednji put prikazan našim iseljenicima u Americi 1928. godine nakon čega mu se gubi trag. ${ }^{29} \mathrm{Na}$ sreću, pronađen je posle 75 godina. Nadživeli su ga, doduše ne zadugo, i njegov bioskop kao i neki njegovi stavovi u obliku usmenog pre-

${ }^{28}$ U verziji filma koju danas imamo a koju je restaurisala Jugoslovenska kinoteka, međunatpisi koji objašnjavaju radnju u datoj sceni obaveštavaju gledaoce da Karađorđe ubija očuha Petronija (Karađorđe, DVD, Beograd: Jugoslovenska kinoteka, 18 min $10 \mathrm{sec}$ ). Međunatpise je 2003. godine napisao Aleksandar Erdeljanović, a „na osnovu izvora korišćenih za film“. А. С. Ердељановић, „Продуцент Светозар Боторић и његови филмови (I део)“, 100. O tome da li je Karađorđe, kao istorijska ličnost, izvršio ubistvo oca ili očuha videti: Михаил Белов, „' ...Сапрела те моја рана ако га не убијеш!' Карађорђе: генеалогија харизме народног вође“, Годишъак за друшвену историју, 2-3, (2004), 7-28.

29 А. С. Ердељановић, „Продуцент Светозар Боторић и његови филмови (I део)“, 99. 
danja. Tako je Kosta Novaković, ,zaokupljen onim starim Botorićevim idejama da je teško održati filmsku produkciju bez sopstvenih bioskopa“, ${ }^{30}$ zakupio najstariji stalni srpski bioskop Pariz u martu 1929. Da je preživeo rat, Botorić bi sigurno imao još ponešto korisno da o zanatu došapne svojim filmskim potomcima.

Do početka Balkanskih ratova u Srbiji je snimljen još samo jedan kratki igrani film (Jadna majka, reditelj Boža Savić, 1912) koji se danas smatra izgubljenim. Producenti filma su bili braća Savić (Pera, Boža i Svetolik), vlasnici preduzeća „Savić-Film i Komp“, koje je u Srbiji zastupalo drugu veliku francusku filmsku kuću Gomon. Što se tiče njihovog jedinog filma, bio je mnogo manje ambiciozan od Karađorđa, što se može zaključiti i po naslovu. Zaplet je bio melodramski i tragičan - udovica poludi nakon sinovljeve smrti i provodi dane u besmislenom očekivanju njegovog povratka iz škole, na putu ka kojoj je on i poginuo. Uprkos velikim planovima koje su imali, braća Savić su po završetku ovog filma, a sa početkom Prvog balkanskog rata, prekinuli proizvodnju igranih filmova a 1914. rasprodali su svoju opremu. Nikada se više nisu bavili filmom, iako su preživeli Prvi svetski rat. Pošto su se i ostale predratne filmadžije okrenule drugim zanimanjima ili izgubile život u ratovima, srpska kinematografija u novoj državi, pod novim imenom, ponovo je krenula od početka, „neopterećena“ nasleđem.

\section{Drugi početak srpskog filma - holivudski način}

Za filmske stvaraoce u Srbiji, Kraljevina SHS/Jugoslavija nije donela mnogo toga novog u prvih desetak godina. Ni zakonski a ni ekonomski situacija se nije mnogo poboljšala u odnosu na predratni period. Sve do 1931. nije bila sistemski regulisana filmska delatnost, a bez pomoći države film se nije mogao stvarati. U boljoj poziciji su bili distributeri i prikazivači filmova jer je film bio popularan oblik zabave pa su njihove zarade rasle, ali su oni bili orijentisani isključivo na uvozne filmove i nisu pokazivali nikakav interes za stimulisanje domaće proizvodnje. Istočni deo nove države je bio razoren ratom i sporo se oporavljao, tako da do 1922. godine nije bilo nijednog pokušaja da se proizvede igrani film. U zapadnim krajevima, pre svega u Hrvatskoj, upravo su to bile godine filmskog procvata. ${ }^{31} \mathrm{U}$ periodu nakon Prvog svetskog rata, u Jugoslaviji su najpopularniji bili američki i nemački filmovi pa su njihova predstavništva imala i najveću ekonomsku moć. ${ }^{32}$ Ipak, situacija u pogledu kinematografije, čak i kad se ona posmatra samo kao reproduktivna delatnost, u celoj državi je bila porazna po brojnim pokazateljima - broju bioskopa, poseti bioskopima, itd. ${ }^{33}$

\footnotetext{
${ }^{30}$ Petar Volk, Dvadeseti vek srpskog filma (Beograd: Institut za film, Jugoslovenska kinoteka, 2001), 279.

${ }^{31}$ U Hrvatskoj je avgusta 1917. formirano Prvo hrvatsko filmsko poduzeće Croatia, sa ciljem da snima igrane filmove. „Prvo njihovo ostvarenje bila je komedija Brcko u Zagrebu (reditelj Arsen Maas, 1917) da bi zatim realizovali film Matija Gubec (reditelj Aleksandar Binički, 1917)... Do kraja rata Croatia je snimila još 5 igranih filmova (...).“ D. Kosanović, Kinematografija i film..., 19.

32 „Godine 1935. od filmova prikazanih u Jugoslaviji 55\% su bili američki a 22,5\% nemački, a sledili su austrijski 7\%, francuski 6,5\%, engleski 4,5\% itd.“ D. Kosanović, Kinematografija i film..., 37.

33 „Po broju bioskopa, i bioskopskih sedišta u odnosu na broj stanovnika međuratna Jugoslavija se nalazila na pretposlednjem mestu u Evropi (samo ispred Albanije).“Isto, 31.
} 
Tokom 1920-ih godina, sa popularizacijom filma, počele su i na teritoriji Srbije da se razvijaju neke forme filmske kulture koje su bile od indirektnog značaja za razvoj kinematografije. Osnivaju se filmski časopisi, filmske škole i klubovi ljubitelja filma. Najpoznatiji i najznačajniji je Beogradski klub filmofila, osnovan 27. februara $1924 .{ }^{34}$ Taj klub je imao oko stotinu članova najrazličitijeg profila, a među njima nekoliko koji će biti veoma značajni za dalji razvoj srpskog filma. To su bili, s jedne strane, osnivači kluba, filmski kritičari, novinari i pesnici Boško Tokin, Dragan Aleksić, Stanislav Vinaver i Milutin Ignjačević, a sa druge, filmofili kao što su magistar farmacije Kosta Novaković i mehaničar Josip Novak. Članovi kluba su vrlo brzo po osnivanju 1924. godine organizovali snimanje igranog filma Budi Bog s nama ili Kačaci na Topčideru. Scenario je napisao književnik Branimir Ćosić, a režirali su ga Boško Tokin i Dragan Aleksić. Snimljen je samo jedan deo filma u dužini od par stotina metara $35 \mathrm{~mm}$ trake, snimanje je prekinuto i nikada nije nastavljeno. Traka je, navodno, kasnije izgorela, scenario još nije pronađen, tako da od filma imamo samo fotografije sa probnog snimanja.

Šteta je što taj film nije snimljen jer bi to bio, sudeći po htenjima njegovih reditelja (pre svega Boška Tokina), izraz onog dela srpske kulturne javnosti koji je bio $\mathrm{u}$ vezi sa avangardnim evropskim umetničkim tokovima a koji je u drugim umetničkim formama (fotografiji, poeziji, književnosti) davao značajne rezultate u evropskim razmerama. ${ }^{35}$ Ovaj neuspeh, međutim, podstakao je na aktivnost grupu manje umetnički a više komercijalno orijentisanih članova Kluba filmofila.

Pobornici holivudskog pristupa filmu, potekli iz Kluba filmofila, bili su Kosta Novaković i Josip Novak. Uz mnoge druge producente i stvaraoce koji su sanjali o „srpskom Holivudu“, ova dvojica su to u dobroj meri i ostvarila, ali ne u pogledu obima produkcije i budžeta svojih filmova već pre svega po načinu naracije i konceptualnom pristupu filmu. Ujedno, gotovo svi njihovi filmovi (osim Novakovićevog Kralja čarlstona, 1927) sačuvani su do danas.

Josip Novak je značajan kao reditelj komercijalnih formi - kratkih igranih filmskih reklama i jednog dugometražnog filma koji je zapravo bio ,reklamno vozilo“ za novootvoreni rudnik „Jerma“ i njegovog finansijera Eskontnu banku. To je film Rudareva sreća (r. Josip Novak, 1928), čija je narativna struktura više bila prilagođena reklamnim zahtevima poručioca nego dramaturškim pravilima, zbog čega ga nećemo ovde opširnije analizirati. Po dramskoj strukturi i komercijalnoj-reklamnoj nameni svakako je u pitanju klasičan, „holivudski“ film.

Kosta Novaković je ukupno režirao dva igrana filma. Kralj čarlstona, koji je izgubljen, i Grešnicu bez greha (1930). Grešnica bez greha je najbolje sačuvan primer za tipičan srpski film tog perioda, zato što je to uspešan pokušaj stvaranja komercijalnog filma po holivudskom narativnom modelu a sa implicitnom nacionalnom tematikom, što su, koliko znamo iz sačuvanih

\footnotetext{
${ }^{34}$ P. Volk, Dvadeseti vek srpskog filma, 274.

${ }^{35}$ Božidar Zečević, u svojoj studiji o avangardi i srpskom filmu, navodi: ,drugi avangardistički filmski scenariji (Lj. Micić, R. Petrović, A. Vučo) nikada nisu, ni u pokušaju, realizovani““. Božidar Zečević, Srpska avangarda i film 1920-1932 (Beograd: UFUS, 2013), 128.
} 
informacija o drugim, izgubljenim filmovima, bila htenja i većine filmskih autora tog vremena. ${ }^{36}$

Tema filma Grešnica bez greha je sukob tradicionalnih i modernih vrednosti u Srbiji tog vremena, sukob prostog naroda i ,evropejaca“. To je tema koja je tipična za književnost Srbije na početku 20. veka. ${ }^{37}$ Film prati sudbinu dvoje verenika, Ljubice (balerina Sonja Stanisavljević) i Nikole (amater Ilija Dragić), koje privremeno razdvaja njegov odlazak u grad na školovanje. Umesto da ostane na selu da ga čeka, Ljubica dobija poziv od porodičnog prijatelja i odlazi u Beograd na školovanje. Dok Nikola uspešno izbegava sve zamke samačkog, studentskog života u velegradu, Ljubica, uz podršku stanodavke Olge, započinje vezu sa Lajošem (Viktor Starčić), za koga se ispostavi da je kriminalac. Lajoš napastvuje Ljubicu, ali ona uspeva da odoli napadima do dolaska policije. Njena reputacija, međutim, uništena je zbog greha koji zapravo i nije počinila. Ne nalazeći spas i razumevanje ni u svojoj porodici (Majka - Persa Pavlović i Otac - Nikola Gošić, poznati glumci Narodnog pozorišta), Ljubica odlučuje da izvrši samoubistvo. Nikola ipak uspeva da je spase. Nakon što Lajoš u zatvoru doživi katarzu i prizna policiji da je Ljubičina čast neokaljana i da ona nije njegov saučesnik, Ljubica i Nikola, uz blagoslov roditelja, vraćaju se u selo gde nastavljaju zajednički život.

Jedna od bitnih karakteristika klasičnog modusa jeste da su fabule obično jednostavne, pa je rediteljska sposobnost da manipuliše implicitnim značenjem priče onaj kvalitet koji te filmove čini značajnim. Elementi na osnovu kojih gledalac konstruiše značenje filma nalaze se koliko u tekstualnom sadržaju filma (u dijalozima, simbolici dešavanja, imenima junaka i dr.) toliko i u načinu njegovog vizuelnog predstavljanja (izboru glumaca, načinu glume, kadriranju, kostimu i sceni). Novaković je ovim filmom pokazao da je vladao osnovnim elementima filmske režije holivudskog tipa i prava je šteta što nije imao priliku da nastavi da stvara igrane filmove jer bi oni bili začetak tradicije holivudskog, „Žanrovskog filma“ koja kod nas do danas nije posebno razvijena.

$\mathrm{Na}$ eksplicitnom nivou, ideja filma je jasna i verbalizovana je na samom kraju filma u vidu natpisa: „Sreća nije u lažnom sjaju i raskoši velikoga grada, već u pitomom selu Šumadije, pod blagim suncem, gde život teče u iskrenoj ljubavi“. Na implicitnom nivou, pretnja tom idiličnom seoskom životu je konkretizovana. Svi koji staju na put Ljubici su zapravo stranci („evropejci“). Neimenovani porodični prijatelj, koji fizičkim izgledom (stas, frizura, brada) i kostimom podseća na Lenjina, kakvog ga znamo sa fotografija i iz sovjetskih filmova, i njegova deka-

${ }^{36}$ Ovde mislimo pre svega na ambiciozne filmove koje je proizvela „Adria-nacional film AD“: Kroz buru i oganj (r. Ranko Jovanović i Milutin Ignjačević, 1930) i Na kapiji orijenta (r. Milutin Ignjačević, 1932). O ovoj produkcionoj kući, njenim osnivačima, njihovim htenjima i filmovima videti: Дејан Косановић, „Адрија-национал фил, АД“, Нови Филмограф, година 2, бр. 4, (јесен-зима 2007), 122-127.

37 „'Napredak', koji često biva viđen kao čudan, radikalizovao je strahove od gubitka identiteta i moralnog urušavanja, koji se artikulišu u delima srpskih književnika Laze Kostića, Đure Jakšića ili Stevana Sremca (odnosno na bosanskoj strani kod Safet-bega Bašagića i Edhema Mulabdića).“ Мари-Жанин Чалић, Историја Југославије у 20. веку (Београд: Clio, 2013), 47. 
dentna sestra Olga (ako smo i sumnjali da li se radi o ruskim/sovjetskim emigrantima njeno ime treba da nam odagna te sumnje), kao nosioci kosmopolitskih i revolucionarnih ideja o emancipaciji žena, zovu Ljubicu u grad inicirajući tako seriju negativnih dešavanja. U značenjskom pogledu posebno je važan lik Lajoša, „hohštaplera“, koga igra tada vrlo poznati hrvatski glumac Viktor Starčić. Ako su „Lenjin“ i sestra Olga, kao likovi, imali funkciju da negativno prikažu ruski i sovjetski uticaj na srpsku mladež, funkcija Lajoša je da otelotvori sve ono negativno što nam dolazi sa druge strane, iz bivše austrougarske imperije i sa Zapada uopšte. Osim izgledom (šminkom i kostimom je postignuto da liči na vampira) i imenom (lajavac, lažov - Lajoš), reditelj je i izborom glumca koji tumači taj lik (svojim privatnim identitetom ,poznatog Hrvata“) gledaocima signalizirao (označio) kako implicitno treba čitati ovaj filmski tekst. Dodatno, teza o svekolikoj ugroženosti Srbije i njenih tradicionalnih vrednosti je naznačena i verbalno - jedan međunatpis nas obaveštava da je Lajoševa najnovija pljačka izvedena u $\breve{S} u$ madijskoj banci. Osim materijalne (lopovluka), ugroženost je i moralna - Lajoš se sprema da „ukrade“ i ono bitnije od novca što Šumadija ima, a to je (devojačka) čast. Razorno dejstvo velegrada, nastalo zbog njegove izloženosti stranim koruptivnim uticajima, pokazano je i kroz likove dvoje Beograđana - stanodavke (igra je čuvena srpska pozorišna glumica Žanka Stokić) koja na različite načine iskušava nevinog Nikolu, i prostitutke, koja pomaže Ljubici da ne završi na društvenom dnu, gde je i sama dospela očigledno istim putem koji preti i Ljubici. Dakle, sadržajem priče ali još više i ,holivudskim“ rediteljskim postupkom, prikazana je pretnja koja srpskom društvu dolazi i sa Zapada i sa Istoka, a koja je već počela da razara gradsku sredinu. Stav autora je jasan - treba se odupreti što pre tom uticaju, i to povratkom tradicionalnim vrednostima koje još uvek čuva srpsko selo.

U pogledu naracije, jasno je da je ovakav zaplet predstavljen na klasičan način: glavna junakinja je psihološki definisan lik koji ima jasne i realistične ciljeve koje, nakon brojnih peripetija i gotovo smrti, na kraju dostiže (happy end). Scene su uzročno-posledično vezane, a kraj zatvoren. To je narativna konstrukcija koja krasi i treći sačuvan srpski film iz međuratnog perioda - Sa verom u Boga (r. Mihajlo Al. Popović, 1932). Ovaj film se smatra najboljim igranim filmom tog perioda koji je sačuvan, i to pre svega zbog autentičnosti prikaza jedne tipske ratne priče. Film se bavi stradanjima u Prvom svetskom ratu, što je bila tema koja je bivala sve aktuelnija kako se četvrta dekada 20 . veka bližila kraju. ${ }^{38}$ Ivan, sin srpskog domaćina, odlazi u rat zajedno sa svojim komšijom Sirotanom. Dok oni ratuju (Sirotan odmah gine), okupator zatvara Ivanovu porodicu - Oca i suprugu Smilju, koja gine prilikom bekstva iz logora. Otac se vraća u selo i sa Bosiljkom, devojkom pokojnog Sirotana, nastavlja da brine o Ivanovom sinu sve do oslobođenja. Ivan se vraća iz rata bez ruke i nastavlja život sa porodicom koju je zatekao. Time je priča o ratnom stradanju zaokružena. Međutim, poslednja scena filma (neka vrsta epiloga) značenjski otvara tematsku ravan filma. Ivan i sin, oslonjeni

\footnotetext{
${ }^{38}$ Prvi svetski rat je tema pomenutog izgubljenog igranog filma Kroz buru i oganj kao i ambicioznog dugometražnog dokumentarnog filma Golgota Srbije (r. Stanislav Krakov, 1940) koji je sačuvan.
} 
o stablo, gledaju srpsko vojničko groblje. Na upitni pogled sina vezan za ruku koja mu nedostaje, Ivan mu odgovara: „Kad odrasteš, kad razmisliš, kaž’će ti se samo" (i ovo je nemi film pa se radi o međunatpisu, koji je ovde naveden u originalu). Nakon toga, na odjavnoj špici, pojavljuju se tri dečaka odevena u nacionalne nošnje - srpsku, hrvatsku i slovenačku, sa velikom jugoslovenskom zastavom u pozadini. Autor je ovakvim krajem očigledno hteo da pokrene pitanje smisla podnetih srpskih ratnih žrtava u kontekstu nove, zajedničke države.

Svi sačuvani međuratni igrani srpski filmovi po načinu naracije su klasični (u značenju koje Bordvel daje tom pojmu), po temama su nacionalno angažovani, a konzervativni po idejama koje su propagirali. Ono što ih karakteriše jeste i tehnološka zastarelost - iako su snimani nakon što se pojavio zvučni film, radi se o nemim filmovima, što odgovara lošem tehničkom stanju u celoj jugoslovenskoj kinematografiji tog doba. ${ }^{39}$

\section{Treći početak srpskog filma - sovjetski tip}

Nakon završetka Drugog svetskog rata otpočeo je proces korenitih reformi društva koji je uključivao i kinematografiju. U svim istočnoevropskim socijalističkim državama, imajući na umu poznatu Lenjinovu izjavu, film je postao „,najvažnija umetnost“. ${ }^{40}$ Zapravo, državu u prvo vreme nije zanimao umetnički aspekt filma već njegova propagandna moć. Otuda će za film već krajem rata biti zadužena Filmska sekcija koja je formirana pri Propagandnom odeljenju Vrhovnog štaba NOV i POJ. Božidar Zečević navodi kao početak formiranja ,novije srpske kinematografije“ još uvek neutvrđen dan oktobra 1944. nakon oslobađanja Beograda, kada na čelo Filmske sekcije dolazi Radoš Novaković. ${ }^{41}$

Kinematografija socijalističke Jugoslavije bila je organizovana po republičkom principu tako da se može govoriti o srpskoj kinematografiji, barem u administrativnom i teritorijalnom smislu. Rukovodioci su bili uglavnom ljudi bez većeg filmskog iskustva, ali sa intelektualnim renomeom ili iskustvom iz drugih umetničkih formi (dobro obrazovani Radoš Novaković i Aleksandar Vučo). Na nižim nivoima hijerarhije vladao je princip političke podobnosti. S obzirom na striktnu kontrolu i „filtriranje“ kadrova, kao i na činjenicu da u predratnom periodu nije ni bilo razvijene filmske proizvodnje, nije trebalo uložiti mnogo truda da se napravi rez u odnosu na prethodni period, da se zanemari, potisne i izbriše sve ono što je rađeno pre $1945 .^{42}$ Ipak, ovaj treći po redu kinematograf-

39 U Jugoslaviji su 1932. godine postojala 184 zvučna bioskopa i 154 nema (ukupno 338). D. Kosanović, Kinematografija i film..., 33. Prvi zvučni igrani film u Kraljevini Jugoslaviji prikazan je u Olimp kinu u Zagrebu, 11. novembra 1929.

40 „U februaru iste godine (1922, prim. - O. J.) Lenjin je ponovo naglasio značaj filma u razgovoru sa Anatolijem V. Lunačarskim: 'Tebe smatraju zaštitnikom umetnosti. Stoga moraš stalno imati na umu činjenicu da je za nas film najvažnija od svih umetnosti'." Mira Lim i Antonjin Lim, Najvažnija umetnost: istočnoevropski film u dvadesetom veku (Beograd: Clio, 2006), 44.

41 Божидар Зечевић, „Радош Новаковић: почетка новије српске кинематографије“, Нови Филмограф, година 5, бр. 7-8, (2009/2010), 59.

42 Američki profesor filma Danijel Gulding (Daniel J. Goulding) svoju knjigu o jugoslovenskom filmu započinje rečima: „Teško je zamisliti beznadniji niz okolnosti za uspostavljanje jedne naci- 
ski početak nije bio samo proizvod rata već i poratne ciljane i planske društvene akcije poništavanja svakog nasleđa.

Preuzet je sovjetski model centralizovane filmske proizvodnje, a sa njim i estetska načela i norme sovjetskog filma revolucionarnog perioda. Sistem organizacije proizvodnje kao i shvatanje uloge kinematografije u socijalističkom društvu odredili su i generalni model naracije. Filmovi su pravljeni tako da zadovolje sledeće ciljeve: ,1) idealističko potvrđivanje i otelovljavanje revolucionarne prošlosti, tj. Narodnooslobodilačkog rata i njegovih heroja, te 2) potvrdu i učvršćivanje revolucionarnoga poleta koji je bio potreban za izgradnju nove marksističko-socijalističke države". 43 Drugim rečima, tematski okvir je bio strogo zadat - scenario je morao biti vezan ili za nedavno završen rat ili za „uspehe“ u razvoju nove države. Iako su ciljevi bili jasni, nedostajalo je sposobnosti i znanja za njihovu realizaciju. Zbog toga je, na osnovu zajedničkog dogovora, 1945. godine došla filmska ekipa iz Moskve i otpočela snimanje koprodukcionog filma U planinama Jugoslavije ( $B$ горах Югославии; r. А. Rom /Абрам Метвеевич Роом/, 1946). Snimanje je trebalo da posluži i za obuku novih jugoslovenskih autora (reditelja, snimatelja, glumaca), ${ }^{44}$ a taj film je trebalo da postane model buduće kinematografske saradnje.

Do kinematografske saradnje sa SSSR-om u planiranom obliku nije došlo, jer se već sledeće godine dogodio ideološki sukob dve države. Film $U$ planinama Jugoslavije imao je premijeru u Jugoslaviji 21. aprila 1947. i nije duže ostao na repertoaru. Danas se često taj film posmatra kao simbolička uvertira u sukob do koga je došlo 1948. godine. Goran Miloradović navodi da se „,već tokom snimanja videlo da se ciljevi autora filma kose sa potrebama i željama jugoslovenske strane“. ${ }^{45}$ Tvrdnja da je film Slavica nastao sa ciljem „da se pobiju osnovne političke teze Romovog filma“ zasnovana je na izjavama Vjekoslava Afrića da je scenario za film Slavica počeo da piše ,gotovo polemišući sa scenaristom tog sovjetskog filma“. ${ }^{46}$ Međutim, ako je politička poruka Slavice o istoriji ustanka u Jugoslaviji i bila suprotna onoj iz filma U planinama Jugoslavije, način na koji je ta poruka filmski preneta nije bio različit. Zapravo, Slavica je u mnogo čemu bila tipičnije delo istorijsko-materijalističkog modusa, samim tim i ideološki rigidnije, nego što je to bio U planinama Jugoslavije. Po ukupnom izrazu to je bio vrlo zastareo film.

onalne filmske industrije od onoga koji je postojao u Jugoslaviji neposredno nakon Drugog svetskog rata. Prije rata, jugoslavenska filmska industrija praktički nije postojala (...)“. Daniel J. Goulding, Jugoslavensko filmsko iskustvo, 1945-2001. - oslobođeni film (Zagreb: VBZ, 2004), 1.

${ }^{43} \mathrm{~J}$. Goulding, $n$. $d ., 8$.

${ }^{44} \mathrm{U}$ izradi filma su učestvovali mnogi od značajnih jugoslovenskih filmskih umetnika ranog perioda, na primer glumci Vjekoslav Afrić (u ovom filmu je glumio dve uloge - učitelja Iva i Dražu Mihailovića), Bojan Stupica (glumio lik generala Romela), Ljubiša Jovanović i Olivera Marković, pomoćnici reditelja su bili Vjekoslav Afrić i Nikola Popović, asistent režije Gustav Gavrin, a pomoćnik snimatelja Žorž Skrigin.

45 Горан Милорадовић, Лепота под надзором: совјетски културни утицаји у Југославији 1944-1955 (Београд: Институт за савремену историју, 2012), 188.

${ }^{46}$ Исто. 
Scenario Slavice je organizovan po dva šematska obrasca. Glavna dramska radnja (borba omladinskih aktivista iz Dalmacije za oslobođenje države i nove društvene odnose) organizovana je po principu ,strukture sukobljavanja“ - mlada Dalmatinka Slavica (Irena Kolesar) i grupa njenih kolega i istomišljenika, kao simbolička predstavnica „obespravljenog radništva i seljaštva“ stare Jugoslavije, bori se s domaćim kapitalistima i stranim okupatorima za slobodu i radnička i ljudska prava (između ostalog i za pravo žena da ravnopravno učestvuju u društvenom životu). Sporedna radnja (otpor koji Slavičini roditelji, kao simbolički predstavnici neobrazovanog i politički nesvesnog dela naroda, pružaju njenom revolucionarnom angažmanu) organizovana je po obrascu ,strukture naukovanja“ - roditelji se transformišu od protivnika svakog sukoba u aktivne učesnike rata i revolucije. Oni se, dakle, kreću od nerazumevanja i neprihvatanja novih ideja do razumevanja i učestvovanja u njihovom ostvarivanju. Ova, sporedna dramska radnja čini i okosnicu značenjskog sloja filma - borba za slobodu traži žrtve i one se moraju podneti zarad višeg, opšteg cilja. Implicitno značenje - da su i žene učestvovale u NOB, neke od njih davši i svoj život, te da stoga imaju pravo na ravnopravan tretman sa muškarcima - dato je preko dva glavna ženska lika, Slavice i njene majke. Film se zato i završava krupnim planovima majke koja, pogođena vešću o pogibiji svoje ćerke, ipak podiže glavu i ponosno i hrabro stupa napred. (Naravno, poslednji kadar filma mora izražavati opšti uspeh a ne ličnu tragediju ili hrabrost, pa u njemu vidimo stanovnike Splita koji nose zastave Jugoslavije sa petokrakom i portret Tita.)

I pored brojnih nedostatka, Slavica je bila veoma gledan film ${ }^{47}$ i uspostavila je osnovne elemente žanra jugoslovenskog ratnog (partizanskog) filma. Odlike tog žanra su postojanje jedne ili više scena borbe partizana sa Nemcima i ,domaćim izdajnicima“, prikazivanje Josipa Broza Tita kao ratnog komandanta i političkog rukovodioca (barem implicitno ili u drugom planu), prikaz stradanja nevinog naroda za koji se partizani žrtvuju i scene herojske pogibije u ime naroda i partije. Na značenjskom nivou, osnovna karakteristika partizanskog filma jeste isticanje ličnog žrtvovanja zarad opštih interesa, kao najveće moralne vrednosti.

O filmu srpskog reditelja, po scenariju Branka Ćopića, Živjeće ovaj narod (r. Nikola Popović, 1947), koji je realizovan u produkciji Jadran filma iz Zagreba neće ovde biti više reči zbog ograničenog prostora. ${ }^{48} \mathrm{O}$ suprotstavljanju centralizaciji filmske proizvodnje u Jadran filmu, sabotažama i odlaganjima koji su se dešavali pri realizaciji tog filma, pisao je Goran Miloradović. ${ }^{49}$

Već sledeće, 1948. godine u jednom od ukupno tri snimljena dugometražna igrana filma napravljen je prvi pokušaj da se na „mekši“ način ispune ideo-

${ }^{47}$ Slavica je imala premijeru 12. maja 1947. i u prvoj godini prikazivanja videlo ju je dva miliona gledalaca na području cele Jugoslavije, a Živjeće ovaj narod (r. Nikola Popović, 1947) više od 1,2 miliona gledalaca. J. Goulding, $n$. d., 21.

${ }^{48} \mathrm{O}$ činjenici da je priča dalmatinskog autora snimljena kao prvi srpski flm a priča srpskog autora iz kraja koji naseljavaju pretežno Srbi kao prvi hrvatski film, Petar Volk kaže: „Verovalo se tada da će se administrativnim uticajem i mešovitim ekipama podstaći integracioni procesi kako bi u svim igranim filmovima što više došao do izražaja duh zajedništva i težnje za jedinstvenim jugoslovenskim filmom“. Petar Volk, Istorija jugoslovenskog filma (Beograd: Institut za film, 1986), 138.

${ }^{49}$ Г. Милорадовић, Лепота под надзором, 246-248. 
loški ciljevi, tako što bi se priča stavila ispred ,poruke“. Sofka (r. Radoš Novaković, 1948) bio je prvi umetnički igrani film snimljen u Srbiji nakon Drugog svetskog rata. ${ }^{50}$ Nastao po romanu Nečista krv Bore Stankovića, ovaj istorijski film je pokazao da postoji mogućnost da se na aktuelna pitanja odgovori metaforički. Naredni iskorak u okviru srpske kinematografije, u pogledu izrazitije žanrovske i stilske raznolikosti, bio je vidljiv u filmu Čudotvorni mač (r. Vojislav Nanović, 1950), što je i prvi film koji je bio otkupljen za prikazivanja u SAD.

\section{Zaključak}

Narativna organizacija i tematski sadržaj filmova posmatranog perioda pokazuju da postoji nekoliko zajedničkih karakteristika u kojima se mogu prepoznati odrazi tadašnjih društvenih okolnosti. Osim što je povratak Karađorđevića na vlast bio uzrok i povod za stvaranje Karađorđa, pa je veza društvenog i narativnog direktna, u kasnijim filmovima je ona indirektna ali ne i mnogo manje vidljiva. Problemi u Kraljevini SHS/Jugoslaviji, posebno u pogledu nacionalnih odnosa, očigledno su kod srpskih autora stvorili potrebu za promišljanjem trenutnog položaja Srbije i vrednosti koje su položene u temelj nove države. Razumljivo je, stoga, zašto se ugroženost, kao osnovni motiv, pojavljuje u gotovo svim međuratnim filmovima (Grešnici bez greha, Rudarevoj sreći, $\mathrm{Ne}$ vinosti bez zaštite), a u filmu Sa verom u Boga se i eksplicitno postavlja pitanje smisla podnetih srpskih ratnih žrtava. Izbor tema jasno reflektuje političku krizu u kojoj se nalazila Kraljevina SHS/Jugoslavija u tom periodu. ${ }^{51}$

U skladu sa prethodnim su i zaključci koje daje analiza rodnog aspekta filmskih narativa. Gotovo u svim filmovima glavni lik je žena i značenje priče vezano je za njenu sudbinu. Ženski likovi najčešće trpe radnju (ona je ,bez zaštite“) i nalaze se u poziciji osumnjičene (ona je grešnica iako je ,,bez greha“). Imajući na umu psihološki mehanizam poistovećivanja žene, pre svega kao majke, sa rodnom grudom („Majka Srbija“, „Majčica Rusija“, „Majko naša Crna Goro“), ${ }^{52}$ postaje jasnija i transpozicija aktuelnih društveno-političkih problema u filmski diskurs. Lakanovsko (Jacques Lacan) gledište, po kojem žena u patrijarhalnoj kulturi simbolički označava muškarca, omogućavajući mu tako da proživi svoje strahove i fantazije, može dobro da objasni učestalost ženskih glavnih likova u srpskom međuratnom filmu kojim, kao stvaraoci, dominiraju muškarci. ${ }^{53} \mathrm{Uz}$ to, u

${ }^{50}$ Ostala dva filma snimljena 1948. godine su Besmrtna mladost (r. Vojislav Nanović) i Život je naš (r. Gustav Gavrin), i oba su zasnovana na dramaturškim pretpostavkama istorijskomaterijalističkog narativnog modusa, i u tom smislu predstavljaju naslednike Slavice.

51 „Suštinu jugoslovenskog problema u međuratnom periodu činio je sukob između centralista i federalista, između srpske državne ideje i hrvatske nacionalne politike.“ М.-Ж. Чалић, н. д., 106.

$52 \mathrm{O}$ psihoanalitičkoj interpretaciji semantičke konstrukcije „,mati Srbija“ kao i sa tim povezanoj edipalnoj bazi narativne veze Karađorđa i njegove majke u folklornom predanju, u: М. Белов, н. д., 23-25.

53 „Budući da se umetnost i drama u velikoj meri bave muškom fantazijom, dramatski prikaz ženske frustracije, javno prikazivanje uspostavljanja harmonije u muškom egu, korisno je i za društvo i u ideološkom pogledu.“ Lora Malvi, „Beleške o Sirku i melodrami““, Vizuelna i druga zadovoljstva (Beograd: FCS, 2017), 61. 
periodu do Drugog svetskog rata srećan kraj imaju filmovi u kojima su glavni junaci žene (Grešnica bez greha i Rudareva sreća), osim Jadne majke, što odgovara realno promenjenom društvenom položaju žena, koje su već u toku Prvog svetskog rata ,počele da preuzimaju značajne funkcije u kući i na imanju, kao i u poslovima u gradu, što je jačalo njihovu društvenu ulogu“. ${ }^{54} \mathrm{~S}$ druge strane, $\mathrm{u}$ filmovima sa glavnim muškim likovima kraj je nesrećan (Karađorđe, Sa verom u Boga i Na kapiji orijenta ${ }^{55}$ ). To i odgovara tradicionalnom, patrijarhalnom pogledu na svet i preovlađujućoj, ,nacionalnoj“ filmskoj temi žrtvovanja - žena garantuje produžetak života i kada se žrtvuje u tom cilju, dok se muškarčeva žrtva završava smrću ili sakaćenjem. U socijalističkoj Jugoslaviji žene dobijaju društvena prava pa im je takva, sa muškim likovima ravnopravna, i filmska sudbina (Slavica gine). Iz svega ovoga sledi da, ako se može uopšte govoriti o ,nacionalnom žan$\mathrm{ru}^{6{ }^{656}}$ u srpskoj kinematografiji, na osnovu dostupnih filmova iz posmatranog perioda, mogao bi to biti žanr socijalne ili ratne drame, sa izraženom melodramskom strukturom i dominantnom temom žrtvovanja.

Kada su modusi naracije u pitanju, iako oni nisu striktno vezani za pojedine države niti za društveno-politička uređenja (osim istorijsko-materijalističkog koji je vezan za ideje komunizma i SSSR), veza se ipak može uspostaviti. Modusi naracije mogu se povezati sa nacionalnim kinematografijama po principu porekla i najvećeg broja tipskih filmova. Stoga se može izvesti uopštavanje pa reći da je umetnički modus najviše vezan za Francusku, klasični za SAD a istorijsko-materijalistički za SSSR. Produkcioni uslovi, koji pospešuju nastanak određenog narativnog modusa, nastaju kao proizvod širih društvenopolitičkih okolnosti pa i geopolitičkih uticaja. U tom pogledu zaključci koje donosi analiza preovlađujućeg narativnog modusa $\mathrm{u}$ srpskom igranom filmu su interesantni po pitanju otkrivanja uticaja velikih sila na srpsko društvo i svedoče o dubini transformacija koje je ono pretrpelo.

U doba Kraljevine Srbije film je generalno još uvek bio u povoju i kao izražajno sredstvo i kao privredna delatnost, tako da za tumačenje stranih uticaja u tom periodu veći značaj ima analiza društveno-istorijskih okolnosti nego samog filmskog narativa. Ipak, gledajući dva sačuvana igrana filma iz tog perioda možemo reći da su ti uticaji dominantno bili francuski.

Kraljevina SHS/Jugoslavija, formirana u vreme zrelog nemog filma $i$ pojave zvučnog, kapitalistička država koja je bila okrenuta ka zapadnoj Evropi i SAD, stvorila je društveni, ideološki i proizvodni kontekst koji je osnažio pojavljivanje klasičnog narativnog modusa (najprisutnijeg u filmovima iz SAD). U međuratnom društvu, koje se industrijalizuje i u kojem jačaju buržoaske ideje, tržište je bilo mera uspeha. Stoga je logično da su brojne filmadžije sanjale o

\footnotetext{
${ }^{54}$ М.-Ж. Чалић, н д., 123.

${ }^{55}$ Zaključujemo na osnovu podataka o scenariju: Д. Косановић, „Адрија-национал филм АД“, $126-127$.

56 „Nacionalni žanr odlikuje nacionalni narativ, lakmus struktura koja sopstvenim strukturalnim i tematskim promenama registruje promene nacije.“ Nevena Daković, Balkan kao (filmski) žanr: slika, tekst, nacija (Beograd: FDU, Institut za pozorište, film, radio i televiziju, Beograd, 2008), 40.
} 
„srpskom Holivudu“ a da su filmovi proizvedeni u takvim okolnostima uglavnom imali klasičnu, ,holivudsku“ strukturu i da su nastajali sa ciljem da na zabavan i prijemčiv način prenesu nekada i važne poruke.

Nasuprot tome, film je u socijalističkoj Jugoslaviji imao drugačiju društvenu funkciju. Njegova forma i sadržaj su bili strogo ideološki kontrolisani, naročito u prvim poratnim godinama. Do 1948. godine društveni poredak i produkcioni uslovi, pa stoga nužno i narativni modus, tipično su sovjetski.

Čim se promenio politički okvir, a posebno nakon 1953. godine i Staljinove smrti, srpski film se oslobodio čvrstih ideoloških stega i povratio raznovrsnost izraza i tematsku širinu. Ti novi tokovi su u periodu od 1948. do sredine 1960-ih uključivali obe, u prethodnom kratkom periodu potisnute, narativne tradicije. Srpskim filmom posle 1948. počinje da dominira umetnički modus, ali su zastupljeni i filmovi „holivudskog“ tipa, tzv. „žanrovski filmovi““. ${ }^{57}$ Međutim, u toku 1960-ih, kada su se sukobile dve filmske koncepcije (žanrovskogkomercijalnog i autorskog-umetničkog filma), definitivno je u srpskoj kinematografiji prevagu odnela orijentacija ka evropskom autorskom filmu. ${ }^{58}$ To je jasno vidljivo u filmovima crnog talasa, koji su izrazito autorski i umetnički, a po opštoj oceni predstavljaju najznačajniji deo istorije srpskog filma do danas. ${ }^{59}$ Sudeći isključivo po preovlađujućem načinu naracije moglo bi se reći da je orijentacija u srpskom filmu nakon 1948. a posebno u periodu od 1960-ih pa do 1980-ih, dominantno bila evropska a u znatno manjoj meri transatlantska. ${ }^{60}$

57 Žanrovski film je izrazit primer holivudskog filma, tj. klasičnog narativnog modusa, čiji je najpoznatiji predstavnik tog vremena bio Živorad Žika Mitrović. „Pod pojmom žanrovski film (ili žanrovski oblikovanog filma) najčešće podrazumevamo, kao i Kit Grant, 'dugometražne komercijalne filmove koji koriste princip ponavljanja i varijacija da bi pričali dobro poznate priče o dobro poznatim ličnostima u dobro poznatim okolnostima'.“" Rafaela Moan, Filmski žanrovi (Beograd: Clio, 2006), 100.

58 ,Zagovornici autorskog filma bili su najuporniji i najjasniji u svojim zahtevima upravo u beogradskom krugu u kojem je i bila formulisana idejno-estetska platforma (...). Oni nisu predstavljali organizovanu grupu koju bi povezivale godine, određeni interesi ili programski ciljevi, već je svako prema svojim mogućnostima i uslovima nastojao da doprinese afirmaciji filma koji je istovremeno označavan kao autorski, ili jednostavno - moderan." P. Volk, Dvadeseti vek srpskog filma, 105-106.

59 „Kritika je šezdesete godine, zahvaljujući ovim vitalnim snagama u srpskom filmskom stvaralaštvu, proglasila najznačajnijim, jer su upravo u njima afirmisane ideje koje su bitno uticale i doprinele preobraženjima izraza u svim filmskim centrima." Isto, 107. Filmovi crnog talasa jesu bili manjinski po oštrini društvene kritike i po ekstremnoj formi, ali ne i po narativnom modusu.

${ }^{60}$ Ako nam kao filmska lakmus forma za „američki uticaj“ služi žanrovski film, onda mali broj takvih ostvarenja proizvedenih u Srbiji pomenutog perioda može potvrditi ovu tezu. Autoru ovog teksta nisu poznata statistička istraživanja na temu zastupljenosti žanrovskog filma u srpskoj kinematografiji za posmatrani period, ali postoje brojne studije čiji autori tvrde da je došlo do gotovo potpunog prekida u produkciji srpskog žanrovskog filma u periodu od 1960-ih do 1980-ih. Videti, na primer: Dejan Ognjanović, U brdima horori - srpski filmovi strave (Niš: Niški kulturni centar, 2007) i Jovan Ristić i Dragan Jovićević, Izgubljeni svetovi srpskog filma fantastike (Beograd: FCS, 2014). Sasvim je drugo pitanje popularnosti žanrovskog narativnog modela kod gledalaca, koja je nesumnjiva jer je on usmeren ka zaradi i kao takav pogoduje estetskim potrebama $i$ kognitivnim šemama prosečnog posetioca bioskopa. Zbog toga, iako obimom manji, film nastao na klasičnim narativnim obrascima je zbog popularnosti možda stvorio utisak da je bio zastupljeniji u Srbiji. Tema ovog članka nije popularnost filmova kod gledalaca u Srbiji, o kojoj je već drugde pisano, nego uticaj društvenih okolnosti na modele pripovedanja koje su koristili stvaraoci. 


\section{REFERENCE}

- Abot, H. Poter. Uvod u teoriju proze. Beograd: Službeni glasnik, 2009.

- Belov, Mihail. „'...Saprela te moja rana ako ga ne ubiješ!' Karađorđe: genealogija harizme narodnog vođe“. Godišnjak za društvenu istoriju, 2-3, (2004), 7-28.

- Bordvel, Dejvid. Naracija u igranom filmu. Beograd: Filmski centar Srbije, 2013.

- Čalić, Mari-Žanin. Istorija Jugoslavije u dvadesetom veku. Beograd: Clio, 2013.

- Daković, Nevena. Balkan kao (filmski) žanr: slika, tekst, nacija. Beograd: Fakultet dramskih umetnosti, Institut za pozorište, film, radio i televiziju, 2008.

- Erdeljanović, Aleksandar. „Producent Svetozar Botorić i njegovi filmovi (I deo)“. Novi Filmograf, godina 1, br. 1, (2005/2006), 92-103.

- Erdeljanović, Aleksandar. „Producent Svetozar Botorić i njegovi filmovi (II deo)“. Novi Filmograf, godina 1, br. 2, (2006), 104-108.

- Goulding, Daniel. Jugoslavensko filmsko iskustvo, 1945.-2001. Zagreb: V. B. Z., 2004.

- Jagodić, Miloš. „Procena demografskih gubitaka Srba u periodu 1910-1921”. Srpske studije, br. 6, (2015), 11-65.

- Jovičić, Stevan. „Kinematografija u Srbiji 1896-1941“. Südslavistik online. Nr. 2 (2010), 23-33. (http://www.suedslavistik-online.de/02/jovicic.pdf, pristupljeno 16. 2. 2019).

- Kosanović, Dejan. Počeci kinematografije na tlu Jugoslavije 1896-1918. Beograd: Institut za film i Univerzitet umetnosti, Beograd, 1985.

- Kosanović, Dejan. „Grešnica bez greha“. Novi Filmograf, godina 1, br. 1, (jesen 2005/zima 2006), 104-106.

- Kosanović, Dejan. Kinematografija i film u Kraljevini SHS/Kraljevini Jugoslaviji 1918-1941. Beograd: Filmski centar Srbije, 2011.

- Lim Mira, i Antonjin Lim. Najvažnija umetnost: istočnoevropski film u dvadesetom veku. Beograd: Clio, 2006.

- Malvi, Lora. Vizuelna i druga zadovoljstva. Beograd: FCS, 2017.

- Miloradović, Goran. Lepota pod nadzorom: sovjetski kulturni uticaji u Jugoslaviji, 1945-1955. Beograd: Institut za savremenu istoriju, 2012.

- Miloradović, Goran. „Celuloidni most: dve suprotstavljene interpretacije Drugog svetskog rata u Jugoslaviji na igranom filmu (1941-1991)“. U: Most u književnosti, istoriji i kinematografiji, naučna konferencija. Urednik Aleksandra Vraneš, 83-109. Višegrad: Andrićev institut, 2017.

- Moan, Rafaela. Filmski žanrovi. Beograd: Clio, 2006.

- Volk, Petar. Istorija jugoslovenskog filma. Beograd: Institut za film, 1986.

- Volk, Petar. Dvadeseti vek srpskog filma. Beograd: Institut za film i Jugoslovenska kinoteka, 2001.

- Zečević, Božidar. „Radoš Novaković: početak novije srpske kinematografije“. Novi Filmograf, godina 5, br. 7-8, (2009/2010), 57-72.

- Zečević, Božidar. Srpska avangarda i film 1920-1932. Beograd: UFUS, 2013. 
OLEG JEKNIĆ, PhD, Associate Professor

Faculty of Media and Communications, Singidunum University

Belgrade, Republic of Serbia

oleg.jeknic@fmk.edu.rs

\section{THREE BEGINNINGS OF THE SERBIAN FEATURE FILM: MODES OF NARRATION AND SOCIAL CONTEXT}

\section{Summary}

This article analyzes the narrative structure of Serbian feature films of the first half of the 20th century. The aim of the research is to show how social circumstances favor certain narrative modes. The author finds Serbian cinematography (referring to the territorial definition of the term) particularly suitable for this research because it is characterized by discontinuity, which was the result of two world wars. Lack of tradition and complete interruptions in the production of fiction films have created conditions in which the formation of a dominant narrative mode were more influenced by social than by professional circumstances at every new cinematic beginning. By exploring the reflections of the social context that are visible in narrative modes, the depth of change that the Serbian society experienced in the observed period becomes more obvious. There are three beginning of Serbian fiction film: in 1911 the first feature film was made in the Kingdom of Serbia, in 1922 production was restored in the Serbian part of the Kingdom of SCS, and in 1947 the first feature film in socialist Serbia was filmed. The basis for the analysis and systematization of film narration is the theory of David Bordwell, which differentiates between three basic narrative modes: classical Hollywood narration, art-cinema narration and historical-materialist narration. The conclusion of the research is that the Serbian feature film was initially influenced by the art-cinema narration, above all French; that the dominant mode between the two world wars was Hollywood narration; and that after the Second World War Serbian feature film was structured in accordance with the norms of the Soviet historical-materialist narration. Despite such discontinuity, some common features link those films: the melodramatic structure of the plot, the female characters as the bearers of meaning, the atmosphere of endangerment, and the necessity of sacrifice for the common good.

KEYWORDS: Cinematography, Narration, Narrative Model, Film History, Dramaturgy, Serbia, Yugoslavia 